Original Research Paper

\title{
Real-Time Data Capture Model for Accelerated Payment of Small-Scale Farmers
}

\author{
${ }^{1}$ Natasha Mwansa and ${ }^{2}$ Jackson Phiri \\ ${ }^{1}$ Department of Electrical and Electronics Engineering, University of Zambia, Lusaka, Zambia \\ ${ }^{2}$ Department of Computer Science, University of Zambia, Lusaka, Zambia
}

\author{
Article history \\ Received: 21-07-2018 \\ Revised: $19-08-2018$ \\ Accepted: 24-09-2018 \\ Corresponding Author: \\ Jackson Phiri \\ Department of Computer \\ Science, University of Zambia, \\ Lusaka, Zambia \\ Email: jackson.phiri@cs.unza.zm
}

\section{Introduction}

As food is an important part of our livelihood, a well appreciated food security shield is required to foster and maintain a nation's economic growth (IFPI, 2014). To properly manage Zambia's National Strategic Food Reserve on the agricultural activities and practices, an organization called Food Reserve Agency (FRA) was established. The FRA manages the national storage facilities, market setting and fixing farm produce floor prices (Simukanga et al., 2018). National strategic food reserve's sole purpose is to manage the exchange and supply of farm produce to cater across the country. This will ensure that all foreseeable shortages are properly managed with an appropriate mechanism to ration what

\begin{abstract}
Most developing countries especially in Africa face a number of challenges in the area of food security. These challenges include proliferation, theft, poor inventory system, poor transport and communication network. Zambia is one of the countries with these challenges and has been losing millions of dollars each year due to various challenges in managing the inventory system. In this paper, we are proposing a model for the inventory system based on Quick Response (QR) and cloud computing for real-time capture of grain bags brought in by farmers at the satellite depot. The government supplies farming input to local farmers and buys the grain back from the farmers. This study is looking at part of the buying process which requires the movement of grain from the local farmer to the government. The grain forms part of the national food storage reserve. The proposed system first requires tagging the grain bags then capture the details of the farmer and attach to the grain bags. Our proposed model based on cloud technologies is integrated with the mobile application used to read the QR code attached to the grain bags. These details are then linked to the details of the farmer in the database. These captured data regarding the farmer and grain bags supplied at the satellite depot are made available to the decision makers in real-time. Out results show that the proposed model will helps to address a number of challenges that the current system has been facing. These include accelerated process of paying the local farmers supplying grain to the government which used to take months. It will also help to give the grain stock statistics in real time per region and the country at large. This model will be very useful for most
\end{abstract} Keywords: Satellite Depot, QR Code, Cloud Computing, Real-Time Data CAPTURE, National Food Reserve Agency is available. The FRA strives to spread across satellite depots in districts to help small scale farmers to sell their farm produce. This is strategic enough to supplement these farmers' efforts by not having them to cover several distances to sell their produce.

\section{Literature Review}

The literature that was reviewed included a background on Zambia's Food Reserve Agency, satellite depot and automatic data capture using QR Code.

\section{Food Reserve Agency}

Since 1991 Government embarked upon creating a market oriented economic system in Zambia 
(Agriculture, 2013). As a result, the agricultural sector, including promotion of agricultural produce, was liberalized and this saw the Government reducing its participation. Government's involvement in the agricultural sector is now restricted to:

1. Guaranteeing the preservation of food security reserves

2. Providing general market sustenance

3. Providing significant market information

4. Providing agricultural credit amenities to smallscale farmers (Simukanga et al., 2018)

Government revised the FRA Act and gave the Agency the extra directive of Crop Marketing (Alinani Simukanga, 2018).

\section{Food Reserve and Marketing Department}

The Food Reserve and Marketing department is in charge of handling the national strategic food reserves (Cynthia Lubasi Muyunda, 2016). The department is composed of four units namely Standards and Quality, Market Information, Operations and Monitoring and Evaluation (Simukanga et al., 2018). FRA buys stock from small scale farmers every year from various satellite depots. The Food Reserve Agency experiences loss of stock because of the manual inventory management system that is prone to human error.

\section{Satellite Depot}

A satellite depot is a marketing center established in outlying or rural areas for the purpose of receiving the crop from farmers (FRAZ, 2017). It is a temporal site that is operated solely for the purpose of receiving the crop from farmers within a given period. Each satellite depot targets to purchase marketable surplus in a given farming community. Some locations have no permanent structures and the Satellite Depot Operators (SDO) is required to facilitate the construction of the temporal storage facility (FRAZ, 2017). FRA operates on a "collect and pay later" principle where farmers deliver to an established satellite depot and later collect payment through an approved financial institution (Chibuye and Phiri, 2017). The crop is later transported to a holding depot through registered transporters (Simukanga et al., 2018). Since 2005, FRA has operated satellite depots throughout the country and purchased designated agricultural commodities which include white maize and paddy rice for national strategic reserve (MAZ, 2013).

\section{Quick Response Code}

Quick Response code (QR Code) is twodimensional barcode that is mobile phone readable that can contain small sets of data and was developed in 1994 by Denso Wave Corporation (ISO/IEC, 2006). It was initially developed as a way to track vehicles as they were assembled and to scan components at high speeds, it has now been adopted into various industries and innovative applications (Zhou et al., 2012). QR Code is recognized as an ISO standard (Narayanan, 2012), it has been defined in the Information technology - Automatic identification and data capture techniques - QR code 2005 bar code symbol specification (ISO/IEC, 2006). This technology is free to use (open standard and public patent), it is also open since its specification is disclosed and the patent right owned by Denso Wave is not exercised (Code, 2011). QR codes are capable of much higher capacities of information storage compared to their traditional bar code predecessors (Code, 2011).

It consists of a series of white and black squares, called modules, placed in a particular order (Han et al., 2017). The $2 \mathrm{D}$ barcodes have become popular because of the widespread use of smart phones which have a camera, the 2D barcodes have various applications such as electronic coupons, advertising, tickets and payment by code scanning billboards and so on. The main distinguishing feature of a QR Code from with a 1D bar code is that it comprises of data in both the upright and parallel orders, whereas a 1D bar code has data in one direction only (Victor, 2012). This is why a QR code holds a significantly larger capacity of data (Code, 2011). In addition, it can encrypt numerous sorts of information or data such as binary data, multimedia data, symbols and control codes (Singh, 2016). A basic barcode holds up to a maximum of 20 digits, whereas QR codes can hold up to 7,089 characters for numeric data, 4,296 characters for alphanumeric data, 2,953 bytes for binary data and 1,817 characters for Japanese Kanji and Kana data (ISO/IEC, 2006). It can encode a website URL, a YouTube video URL or any social media links, geo-coordinates, email addresses, email message and so on (Singh, 2016). QR Code is quicker to read than other two-dimensional code, because it comprises of three large square shapes in the corners that are used for position detection (ISO/IEC, 2006). Additionally, the shapes are used to sense the size, the angle and the outer shape of the symbol. When a reader scans a symbol, it first detects these shapes (Chin and Chen, 2013). Once the position patterns have been sensed the scanner can rapidly read the inside-code in all directions (Chin and Chen, 2013). The inside code comprises of several small blocks where the information is encoded (Narayanan, 2012). The decoding speed of the QR Code can be 20 times faster than that of other 2D symbols (Code, 2011). The structure of a QR code is shown in Fig. 1. 


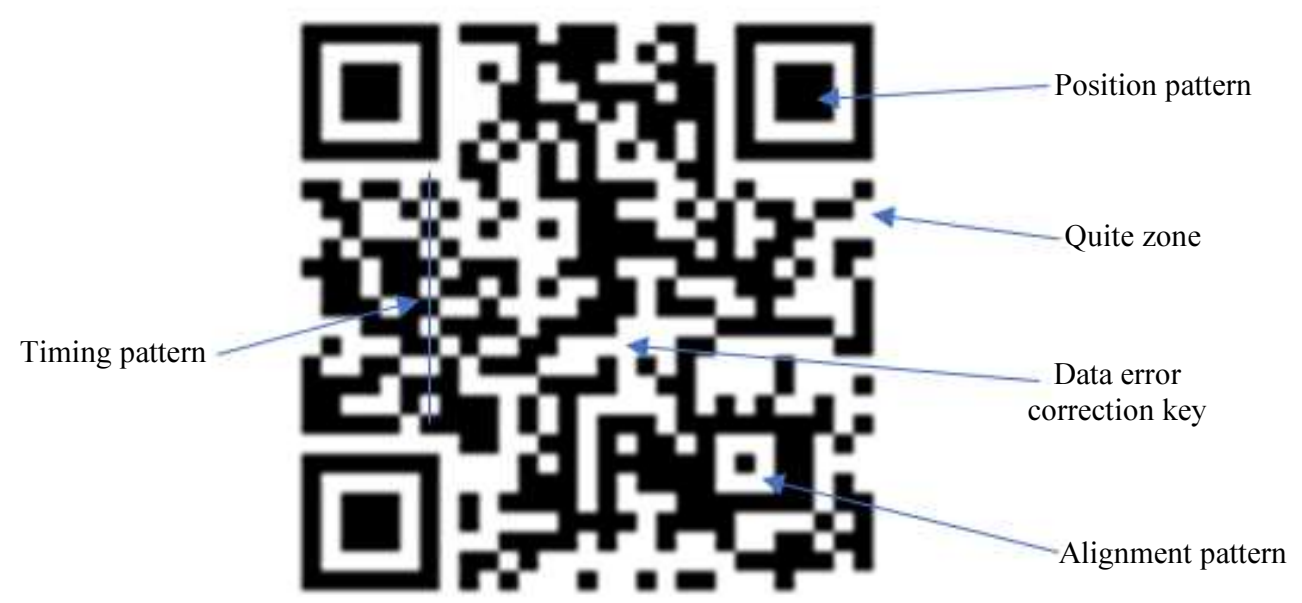

Fig. 1: Example of a quick response code

The elements contained in a QR code are the following:

1. Position Pattern/markings. Three big squares in the corners used for detecting the position, the size and the angle of the QR Code (Chin and Chen, 2013)

2. Alignment Pattern/markings. A pattern used for correcting the distortion of the QR Code. These distortions could occur for example when attaching the codes onto a curved surface (Chin and Chen, 2013)

3. Timing Pattern. It consists in white and black modules arranged alternately and placed between two position patterns. It is used to determine the central coordinate of each cell in the QR Code (Narayanan, 2012)

4. Quiet Zone. A margin space that makes easier to detect the QR Code from its surroundings. At least four cells are required for the quiet zone (Chin and Chen, 2013)

5. Data error and correction keys. The area in the QR Code that contains the actual data (for example a URL) encoded in binary numbers

\section{Methodology}

The following procedures were followed in this study: Firstly, business process mapping and modelling was done to find out how the satellite depot runs its day to day business, from this a model was designed to aid the automatic data capture of the grain bags.

\section{The Current Business Process}

Farmers with bags of grain transport them to the satellite depot. When the farmer arrives at the satellite depot, he or she registers the quantity of bags with the security guard. Once this process is done the farmer gives the SDO an ID (NRC) then it gets verified, afterwards the bags of grain are then opened and put on a sieve for cleaning, once the grain has been cleaned it is transferred to standard FRA bags, the bags are then weighed, each standard bag should weigh $50 \mathrm{~kg}$, at this point the total number of bags supplied by a particular famer is determined. The SDO at this point produces a Produce Receipt and Certification Note (PRCN). The PRCN issued should be marked on each bag supplied by the farmer before stitching. This number is written on the side of the bag using permanent markers provided. Marking on the sides preserves the writings from abrasion and makes it visible on the stack. The bags are then stitched, it is done manually through the use of bailing twine and locally made needles. The bags are then stacked onto wooden platforms or slabs. The stacking is done in a compact and countable pattern. At the end of the day, the satellite depot should be left in good order. Stocks should be reconciled by comparing the book value and the physical count. All documentation is paper based and formats are provided as seen in Fig. 2.

\section{Business Process}

Maize is sourced from the villages situated in the districts. Small scale farmers bring their harvested maize to a central place in the village (satellite depot). The maize is initially brought in their own maize bags; at a later stage the farmer is required to then purchase the FRA standard bags at a small fee and transfer the grain once its cleaned. The farmer provides an NRC and an E voucher card to the SDO. 
If the farmer has not been registered in the database he/she will have to go through the farmer registration process and an E voucher card will be produced for them. After the capturing of the information the farmer's photo is then taken and attached to his information on the database. An Identification card is then printed out. This ID is what the farmer will be using each time he or she wants to sell stock to FRA. The ID will also contain a QR code which when scanned will bring up the farmer's information. The depot officer will scan the ID to verify the farmer details. Once the ID is scanned the farmer then proceeds to the next stage. In the next stage, the bags of maize are taken out of the bags for cleaning. Cleaning grain means removing all the materials other than the grain. After the cleaning process the bags of grain are then transferred to FRA standard bags. At this point the bags are put on the weighing scale for weight verification, each standard bag should weigh $50 \mathrm{kgs}$. When the weight is verified the bags of maize are tagged with QR Code. This is done by adding the grain bag into the system and producing a QR Code for it as seen in Fig. 3. The serial number will be 29 digits.
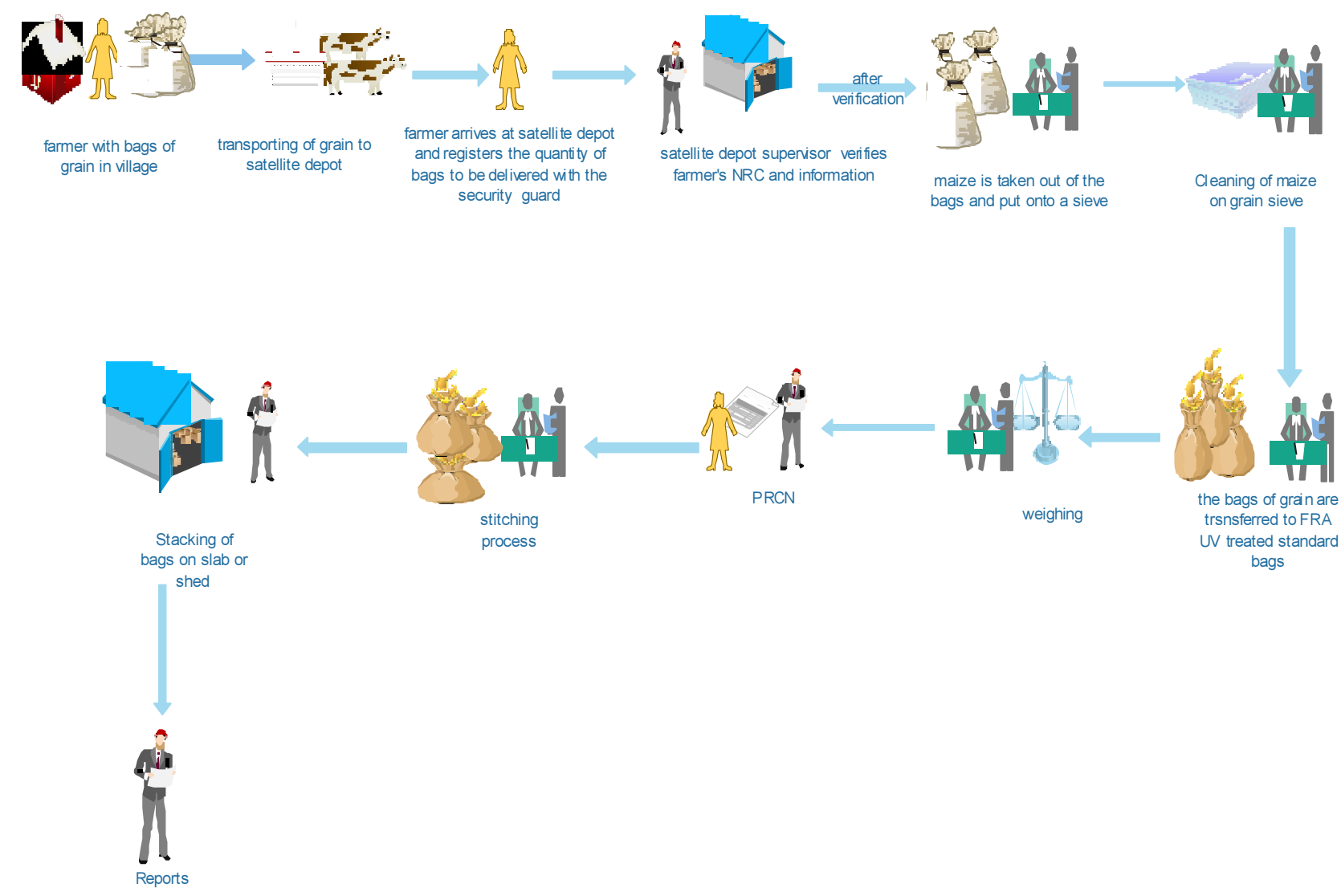

Fig. 2: Current satellite depot business process

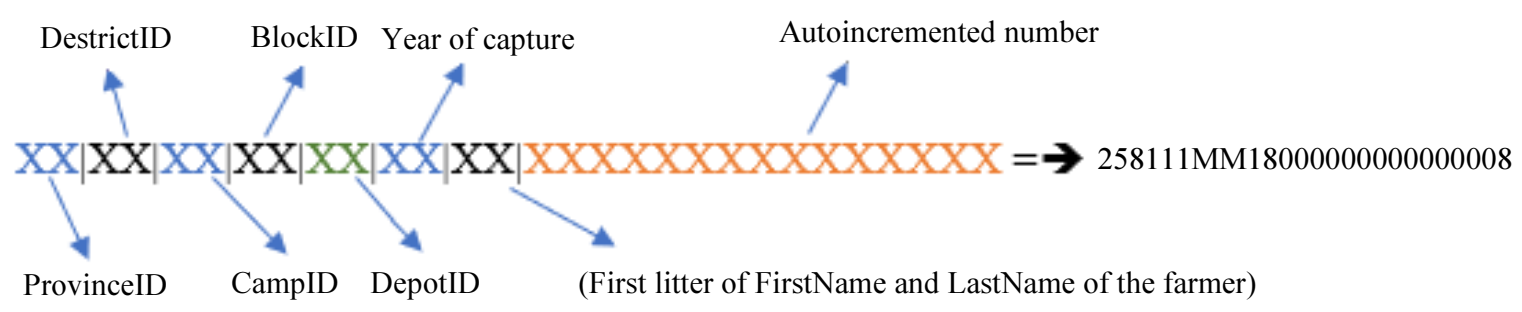

Fig. 3: 29 digit serial number 


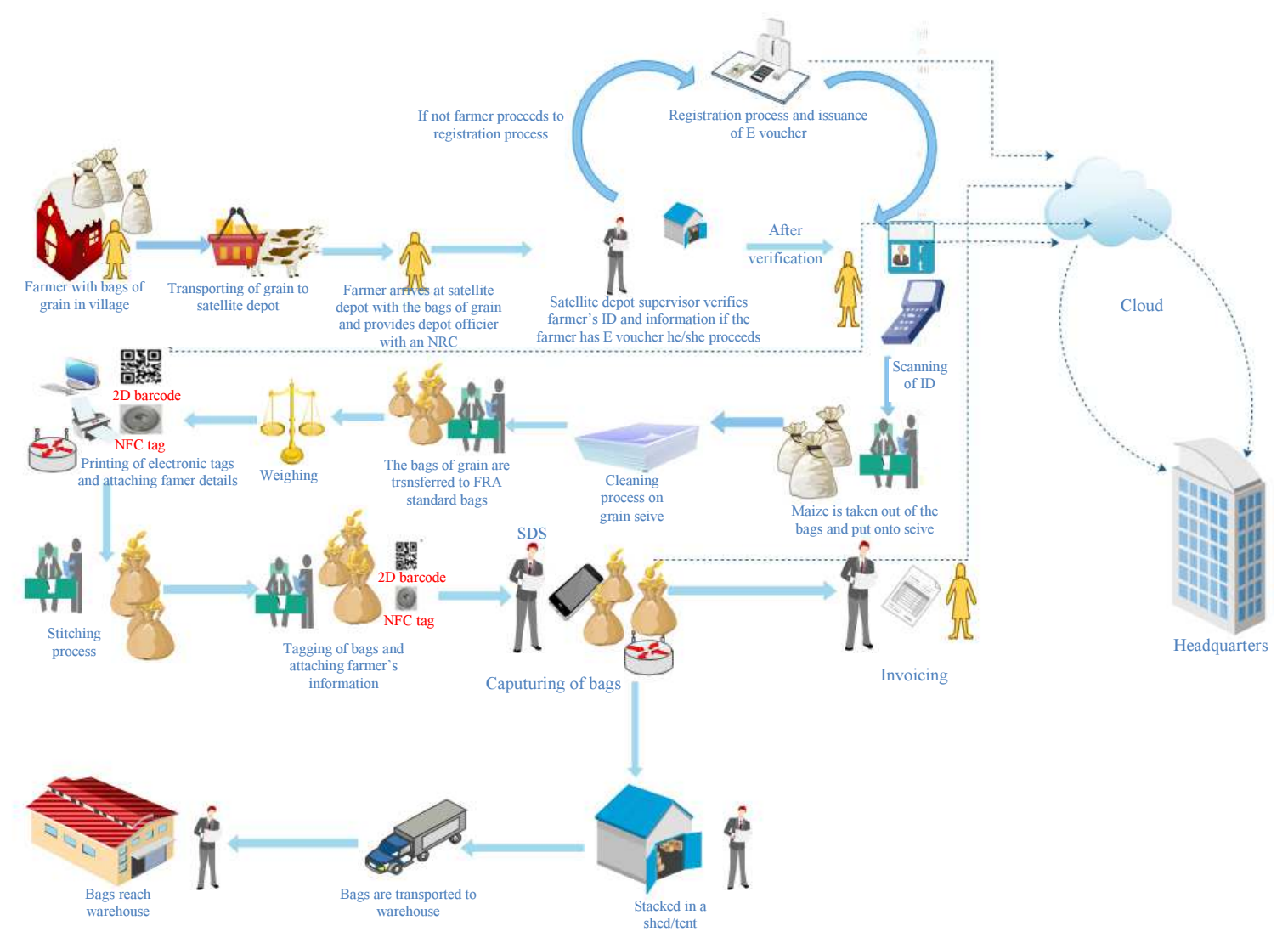

Fig. 4: Current satellite depot business process

At this stage the bags are stitched. The SDO uses the GIMS mobile application to scan the bags. Once the bags are scanned the officer then uploads the information onto the cloud-based database (Gautam et al., 2010). This is done in real time (Nasr and Elbooz, 2018); this information can be viewed by anyone who has authorization from any location. The system then generates a report or invoice for the farmer. The depot officer then stacks the bags of maize onto the slab or shed as seen in Fig. 4.

\section{Generation of QR Code for a Grain Bag}

The output should have the following values:

Province ID, District ID, Camp ID, Block ID, Depot ID, first letter of First Name and Last Name of the farmer, Year of Capture and an auto incremented number e.g., $258111 \mathrm{MM} 18000000000000008$.

Steps in actual generation is seen in the flow chart in Fig. 5.

\section{Steps in QR Code Generation}

\section{Step 1: Data Analysis}

The first stage is trying to identify the four modes for encoding text i.e., numeric, alphanumeric, byte and Kanji. Once established, the next check is whether the mode encodes the text as a string of bits ( $1 \mathrm{~s}$ and $0 \mathrm{~s})$ and the conversion of text into bits used in the shortest possible way.

\section{Step 2: Data Encoding}

Data encoding involves encoding the text once the encoding mode is identified. The output established is the conversion of the string of bits into data code words that are each 8 bits long.

\section{Step 3: Error Correction Coding}

This stage implements error correction with the bits generated using Reed-Solomon error correction process. The QR scanners must be made to read both the data code words and the error correction code words.

\section{Step 4: Structure Final Message}

The data and error correction code words generated must be arranged in proper order i.e., blocks under this stage.

\section{Step 5: Module Placement in Matrix}

At this stage, the bits in the QR code matrix are placed in a specific way and patterns i.e., boxes on the three corners. 


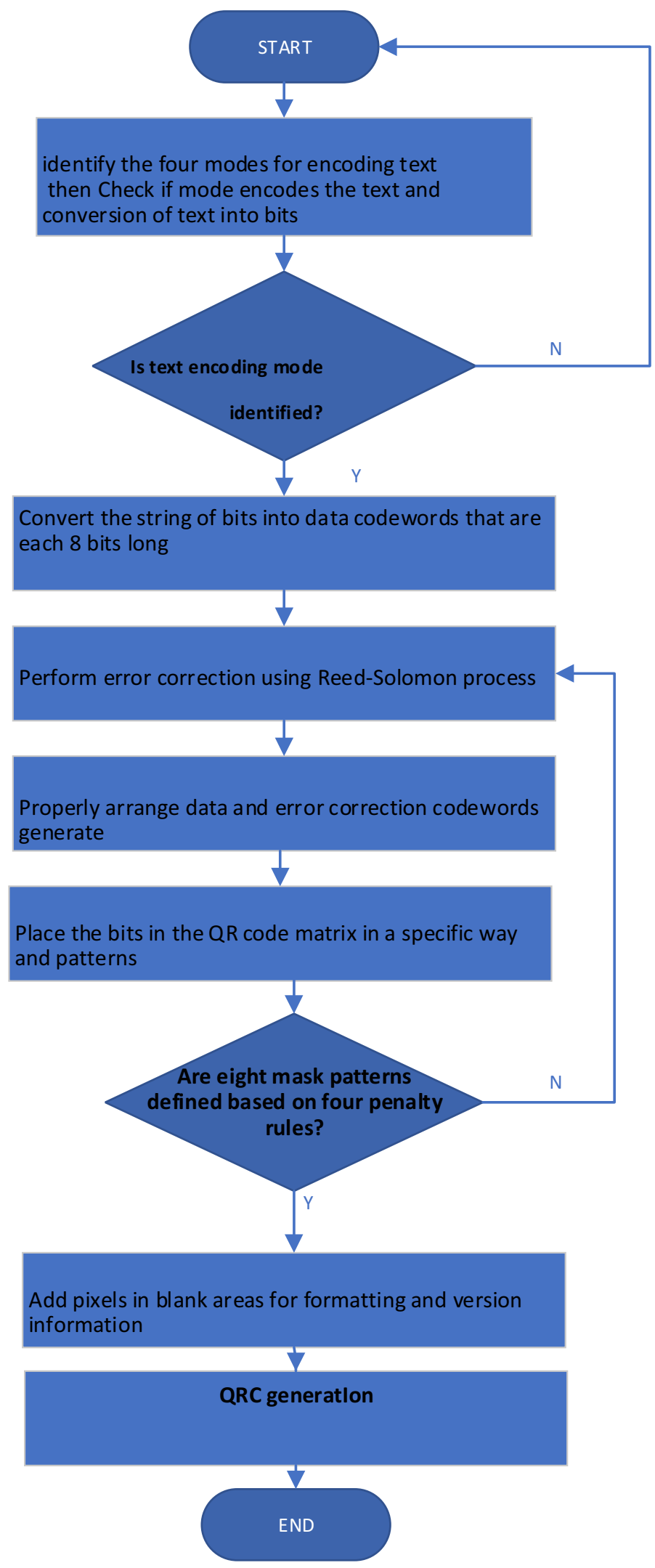

Fig. 5: flow chart of QR code generation 


\section{Step 6: Data Masking}

Data masking involves defining eight mask patterns, each of which altering the QR code according to a particular pattern. Each masked matrix is evaluated based on four penalty rules with the view of having the lowest penalty score.

\section{Step 7: Format and Version Information}

The last stage involves adding pixels in blank areas for formatting and version information.
Generation of QR Code with Auto Incremented Digits

The QR code value has some digits based on the farmer details and an Auto incremented digit value as one string (Chang, 2014).

To make up to the required 29 digits of the QR code, we generated some random digits like:

258111MM18000000000000008 Figure 6 illustrates the process

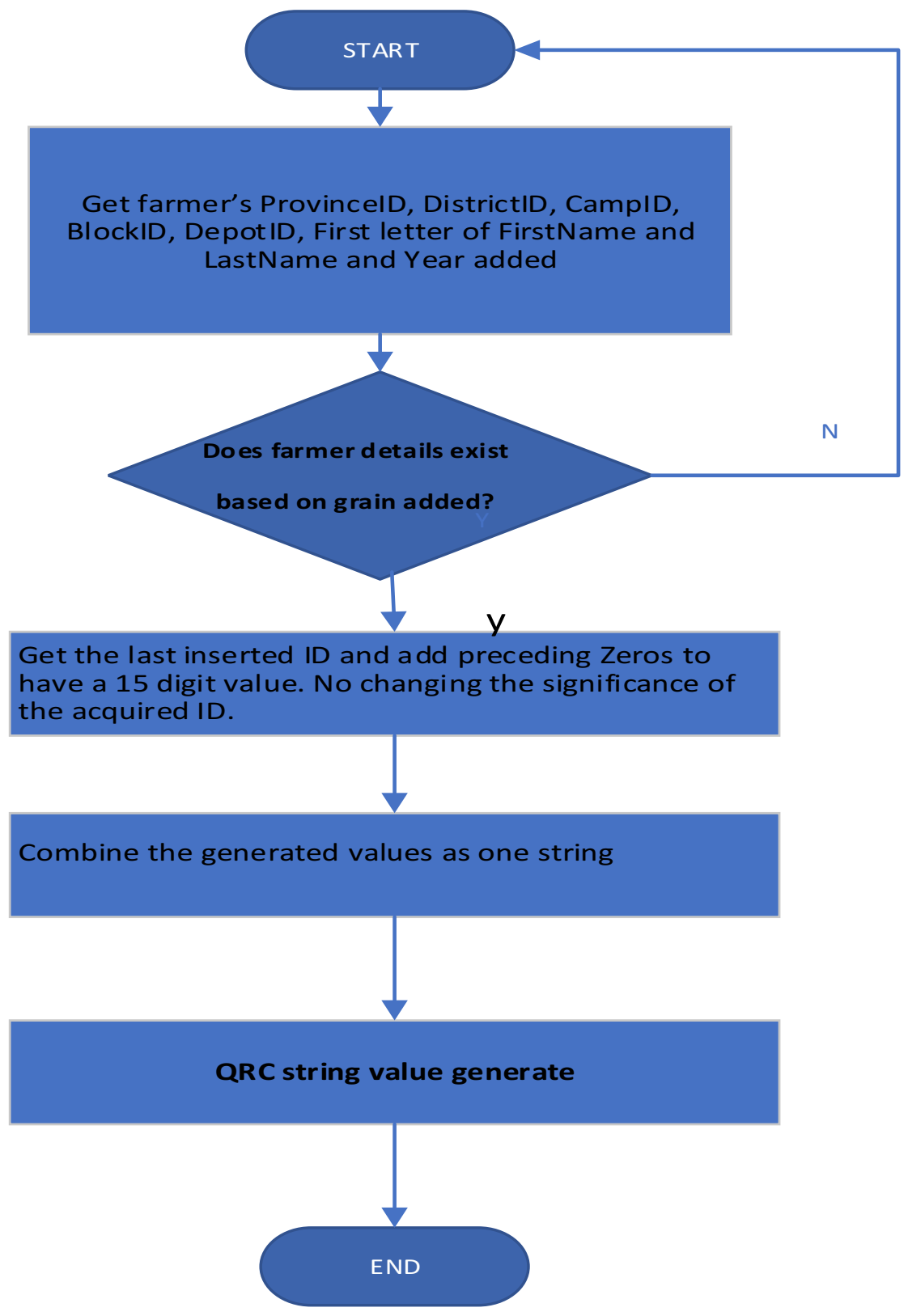

Fig. 6: Auto increment flow char 


\section{Generating the QR Code Value for Grain Bag}

The QR Code value is made up 25 digits string which is generated from the farmer's Provincewide, DistrictID, CampID, BlockID, DepotID, first letter of FirstName and LastName, Year added and 15 auto incremented values for example 258111MM18000000000000008.

\section{The Sequence}

\section{Step 1: Farmer Details Existence}

The first step is checking through the database to see if the associated farmer details exist and they have the valid details. This is also a validation check.

\section{Step 2: Generate Index Year}

This step involves getting the year part of the date from the current date when details are being captured.

\section{Step 3: Generate Name Initials}

The next step is getting the first letter from the farmer's first name and last name. A variable is set in the stored procedure whose values are generated from the farmer details table using an imbedded SQL statement.

\section{Step 4: Generate Geographical Location IDs}

This step involves getting the system IDs of the farmer's Province, District, Camp, Block and Depot.
This is a variable whose which is generated using an SQL statement in the stored procedure.

\section{Step 5: Generate the 15 Digits Auto Incremented} Number

The stage picks the auto incremented number from the "LAST_INSERT_ID ()" MySQL function, which basically picks the table row's last inserted ID of this record's value as incremented on every entry. To make up the required 15 digits, we incorporate the MySQL "LPAD ()" Function with zeros, which will be added to precede the last inserted ID to avoid changing the significant value.

\section{Step 6: Combining all Generated Values}

All the generated values in the above steps are now joined as one value using the MySQL "CONCAT ()" Function. This becomes the QR code value which is then output to a PHP file for attaching to the QR code generator.

\section{System Architecture}

The diagrammatic representation of the system architecture of the QR code and GIMS for FRA is shown below.

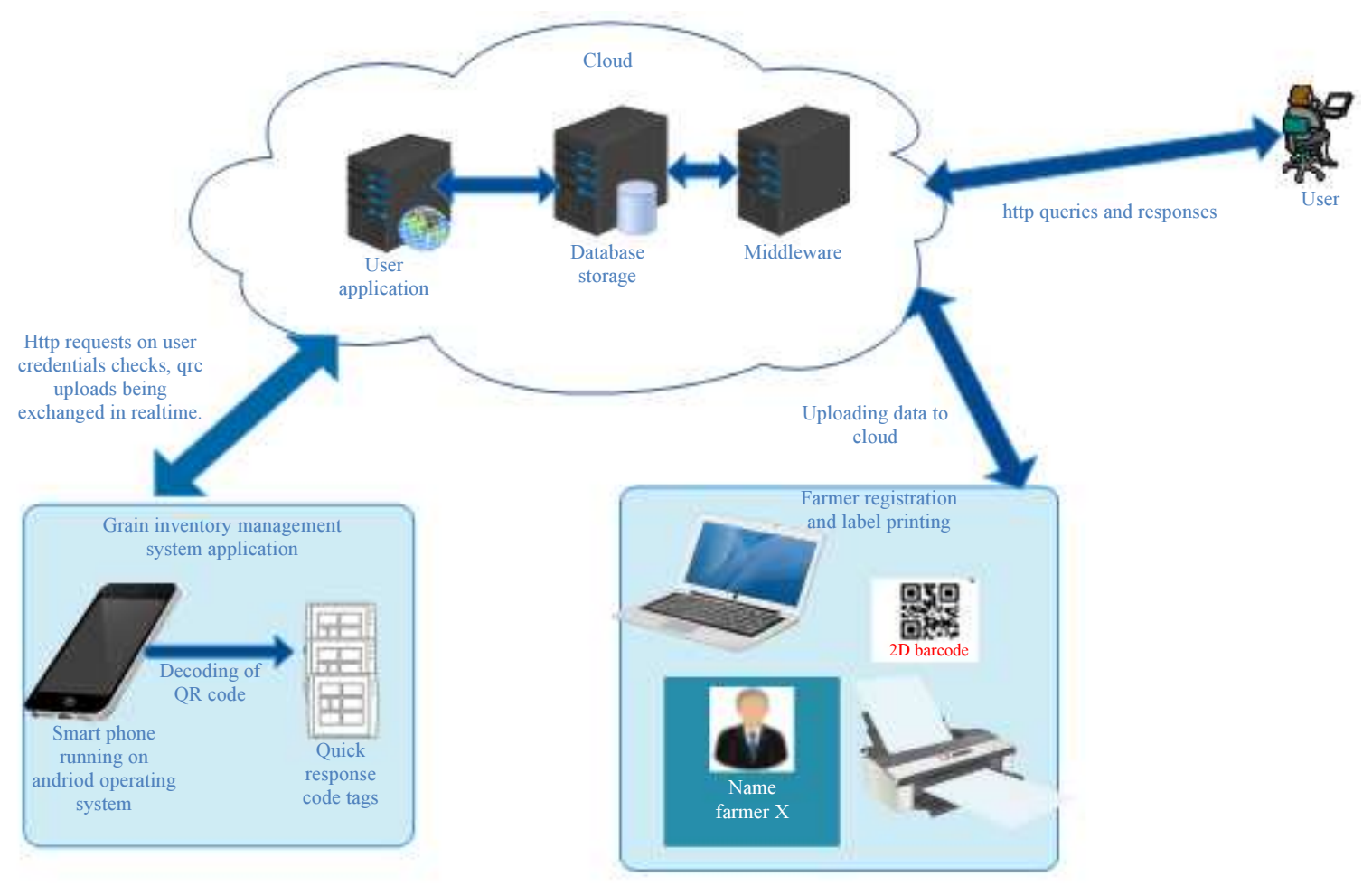

Fig 7: System architecture 

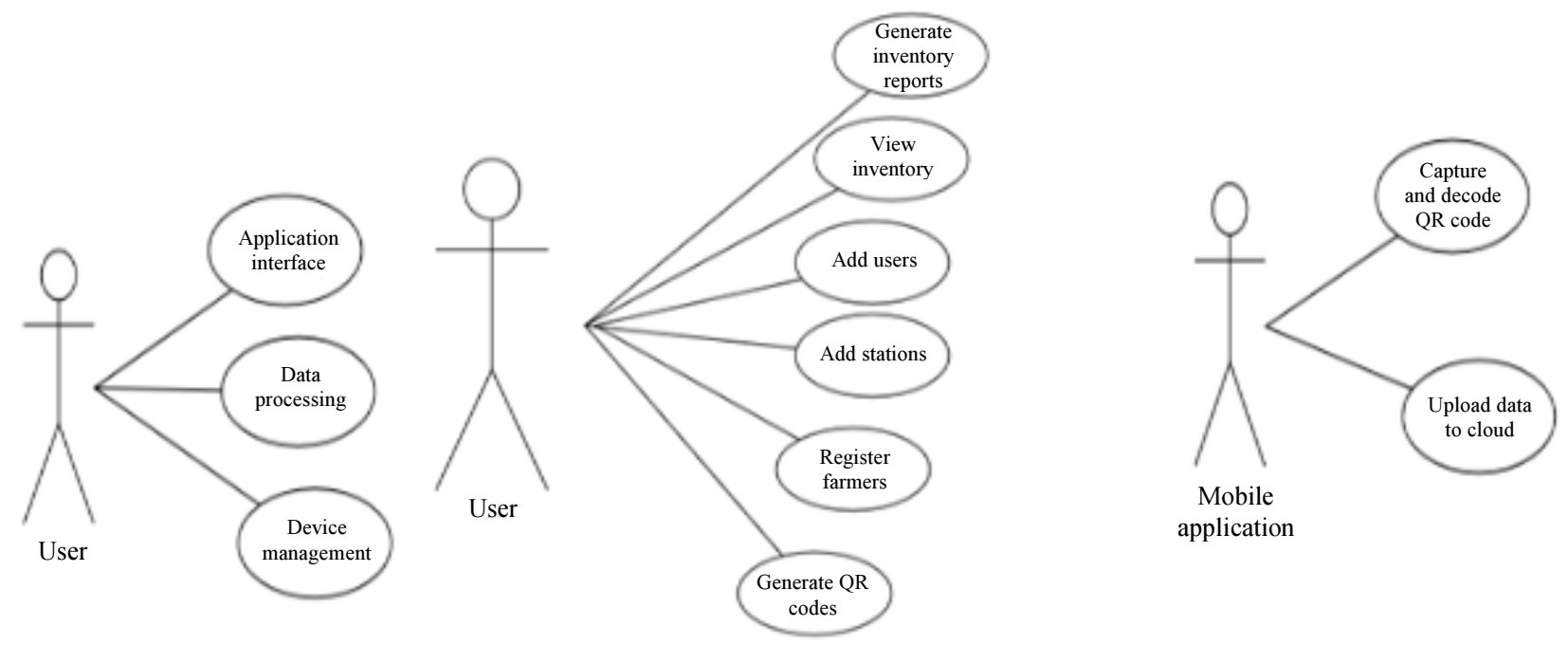

Fig 8: Use case diagrams

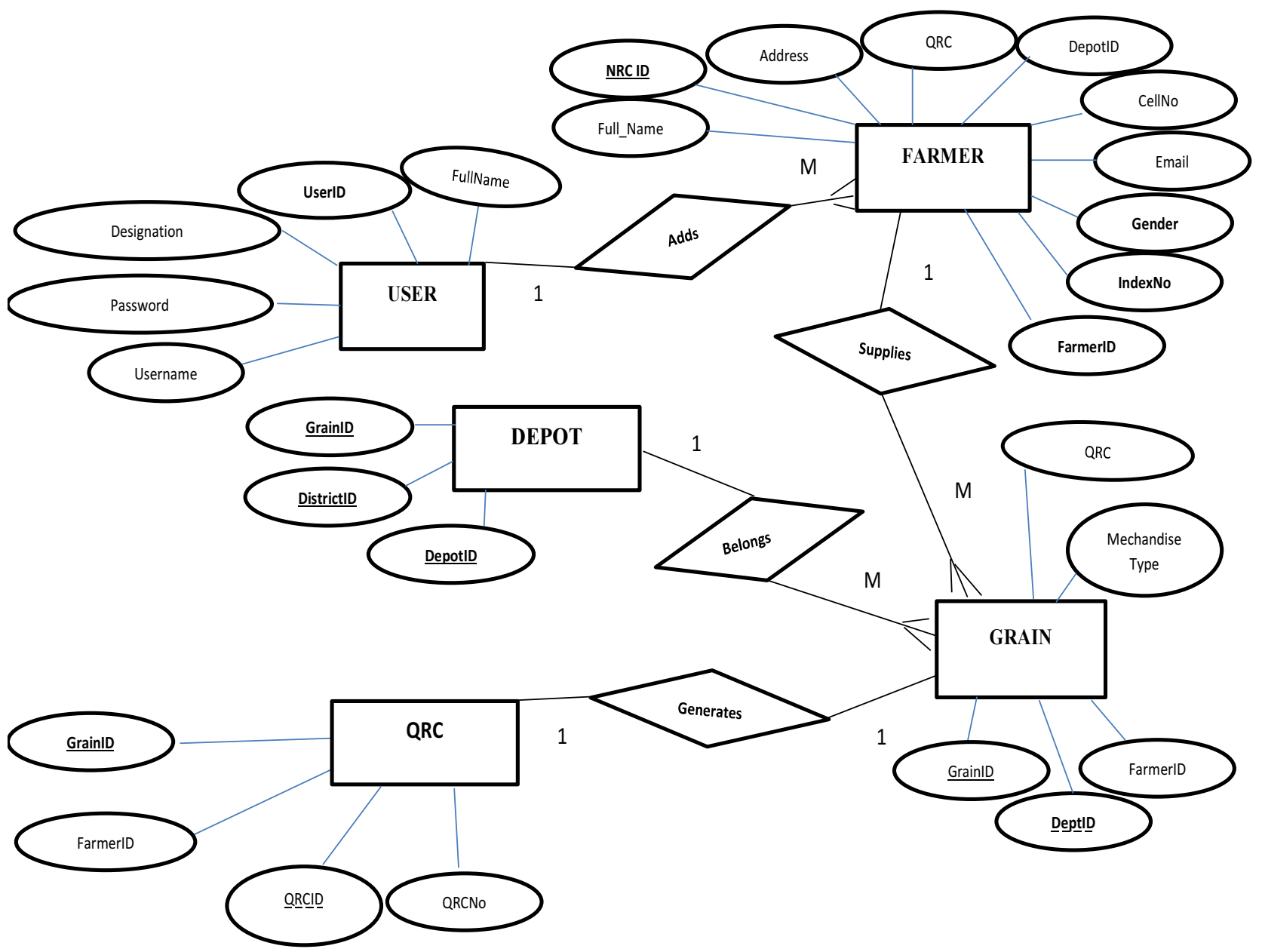

Fig 9: Entity relationship diagram 


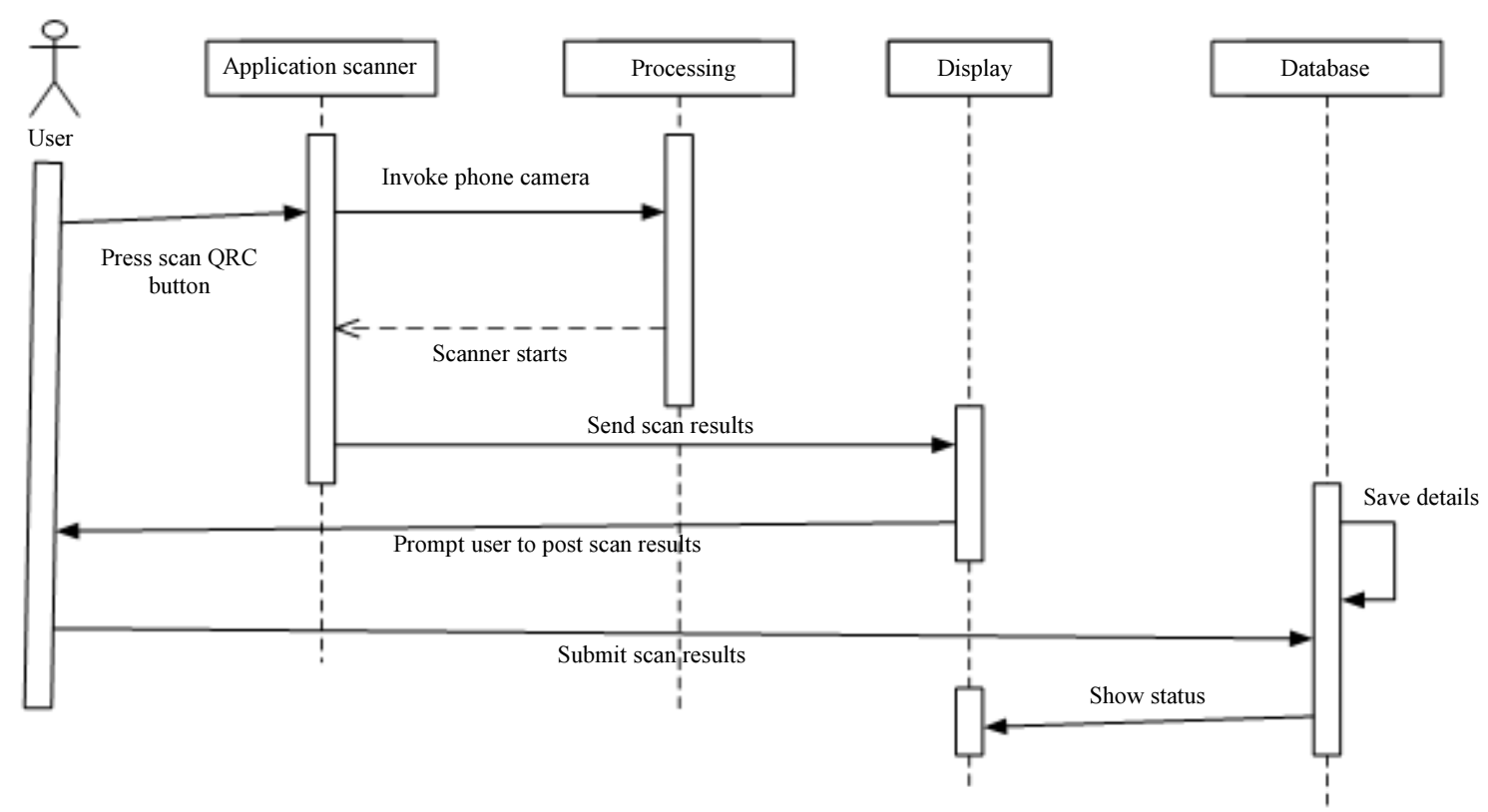

Fig. 10: Sequence diagram

The architecture has three main components as shown in Fig. 7. The components are:

1. The mobile application (Borhan et al., 2018) and hardware constituting the mobile phone and tags

2. The cloud database constituting the middleware (Khunt and Prabu, 2018)

Database storage and the user application and the printing system which will generate the QR codes

\section{A. Use Cases}

As shown in Fig. 8 the main actors of our system were the middleware, mobile application and application Users. The mobile phone application is responsible for decoding of the QR codes and recording the captured inventory stock simply by scanning the bags and sending the captured information to the database. The mobile application middleware is responsible for retrieving data from the mobile application integration and control. The users at the application interface first $\log$ into the system and then they can generate inventory reports, view inventory data, add users, add stations, register farmers and generate QR codes.

\section{Entity Relationship Diagram}

Figure 9 shows an entity relationship diagram model which shows the entity sets stored in the database. It illustrates the logical structure of the database. The main tables are farmer, depot, user, grain and QR Code. The relationship is such that before any other table is fed with data, the user table has to be populated. The user table then provides information on which users can access the system to add the Depot details. Then farmer details are then captured to provide details on capturing grain details to finally give input to the actual grain table for scanned grain bugs. The tables are interrelated to offer strong constraints and data integrity.

\section{B. Sequence Diagram}

Figure 10 shows a sequence diagram for the "Read QR code" from the mobile application:

1. User starts the application

2. User clicks on the scan QRC tab from Main Menu

3. User clicks on the Scan Card Button, QR Code Scanner activated

4. User is required to scan a $\mathrm{QR}$ code when phone camera is invoked

5. Information is retrieved and extract by the scanner

6. Information is decoded and saved to the database

\section{Results and Discussion}

The aim of this study was to develop a technique to improve the capturing of grain at the FRA satellite depot, using a for grain inventory management system 
based on Quick Response Code, cloud database and a mobile application to aid the Food Reserve Agency (FRA) in the capturing and tracking of grains as well as to improve on security and minimize pilferage. From the current business process at the satellite depot it was discovered that FRA employees use manual methods to count bags of grain and invoicing. This method is tedious and time consuming. Farmers can even take up to 3 months before they receive payment because stock taking of records and bags of grain have to be verified. An automated system can help in the decrease of errors caused by visual identification and manual counting.

Figure 11 shows the new farmer registration form. This form also has strong validation checks on required fields and uniqueness of the National Registration Card. When the farmer comes to the depot, we check through the database and see if their details exist. The search criteria is by index number, full name or NRC. If their details exist we reserve them for capturing their grains. If they are not on the database we capture their details. The newly added farmer is now assigned an index number and QR code for tracking.

Figure 12 shows how to capture grain bag details that a farmer brings. Basically, all the grain bags that a particular farmer brings, should be linked to them. The grain bag details are by the type of merchandize and depot were the grain bag was received from. At success capture a unique QR code for each bag is generated based on the captured details. This means that the farmer details should be first captured before capturing grain details.

Figure 13 shows the reporting aspect of the system. Depending on the search criteria farmer details are returned in a report format of either excel or pdf. We can choose from district, satellite depot, gender and finally a report period. This helps to give a high-level representation of the records currently on the database.

Figure 14a shows the landing page on the mobile application after successfully logging onto to it. It has a button for scanning a QR code and a link to a page for handling NFC. Once the Scan QRC button is prompted, a camera is invoked and scanning starts. The instruction is the camera scanner should be placed on the QR code image to read its contents. Figure $14 \mathrm{~b}$ shows an alert of a QR code that has been scanned by the mobile application. This comes once the application and QR code image communicate successfully. The value is further put on a text field to provide a mechanism for posting to the server database.

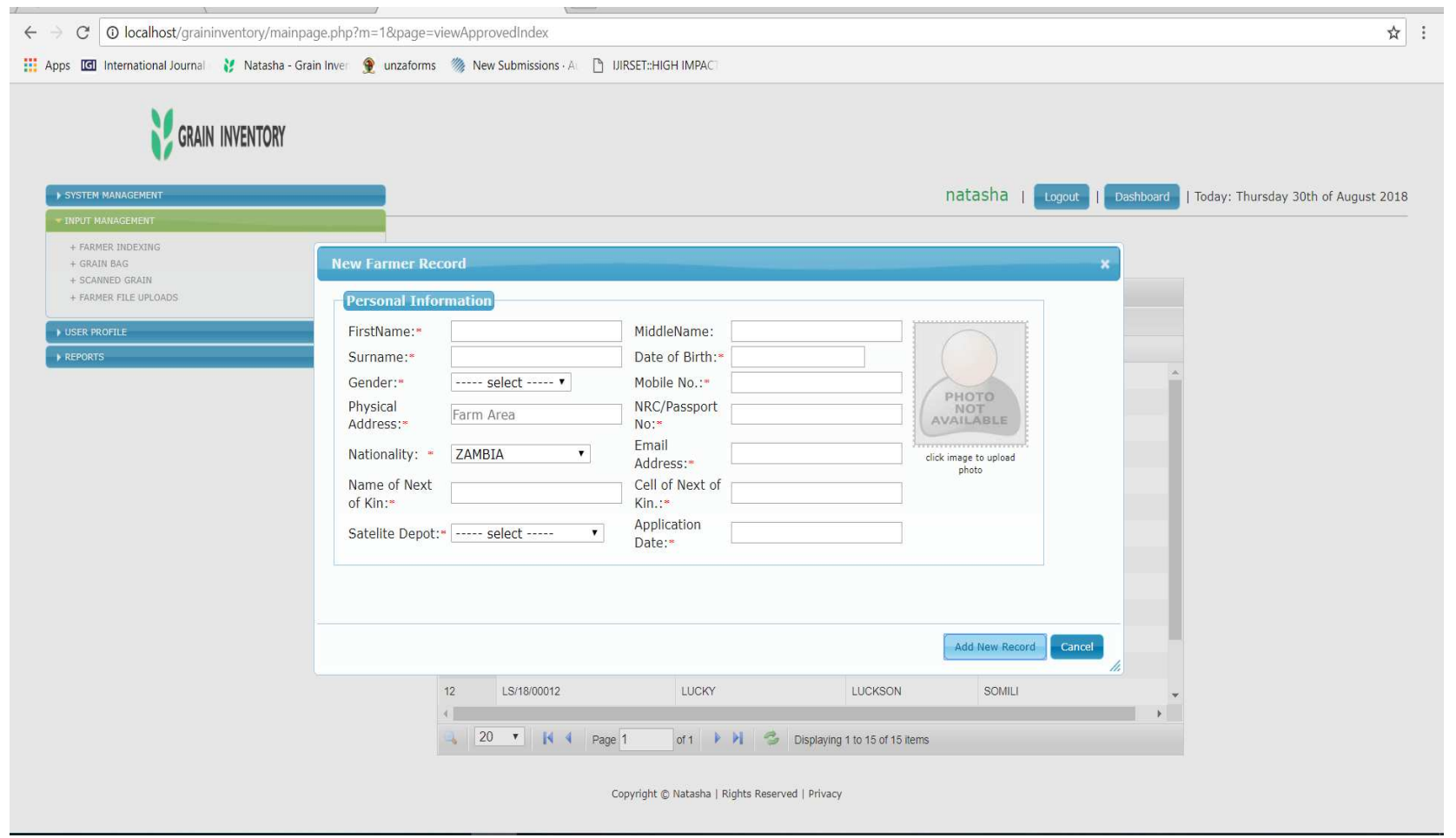

Fig 11: New farmer registration form 


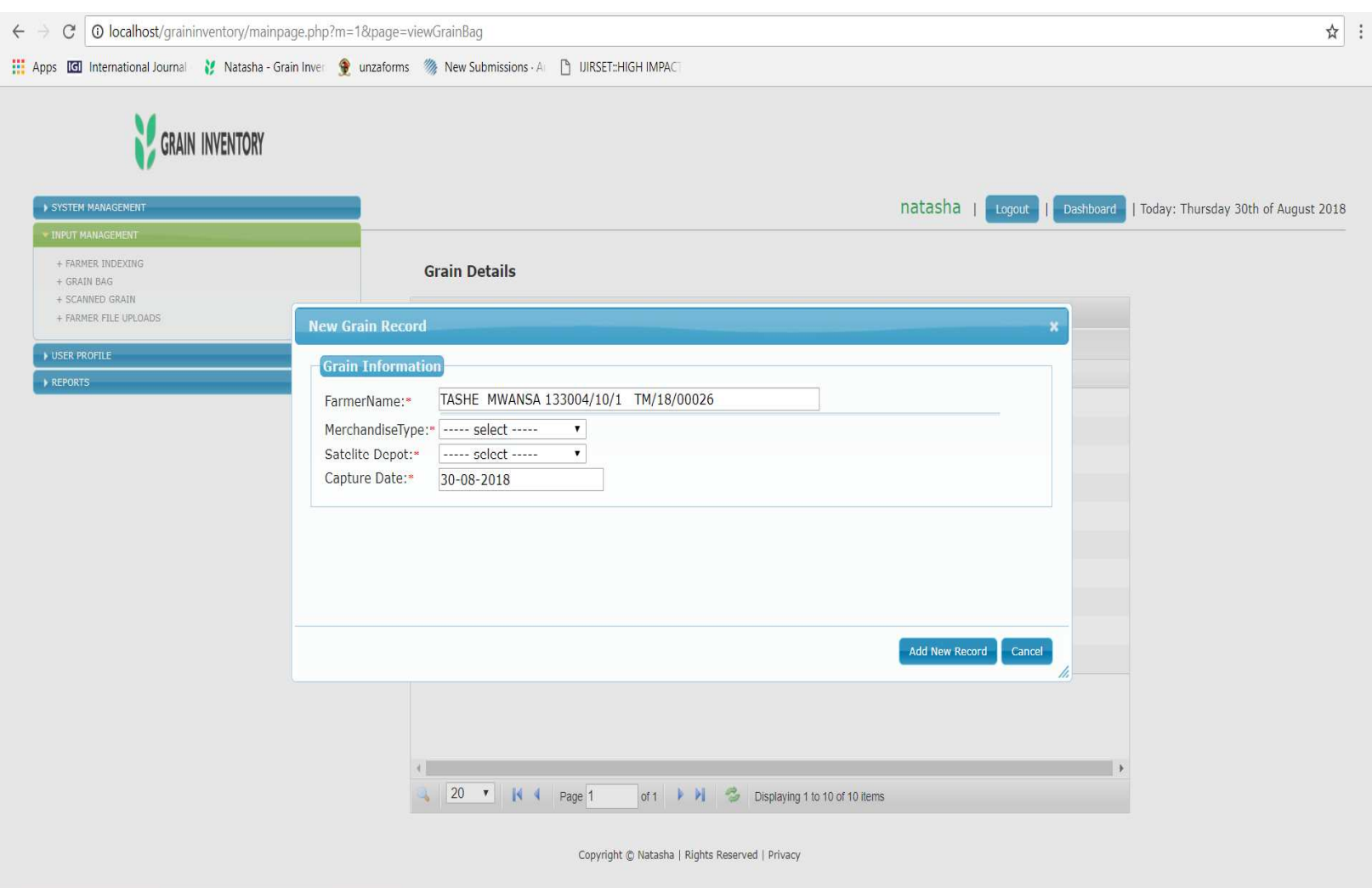

Fig. 12: Adding a new bag of grain

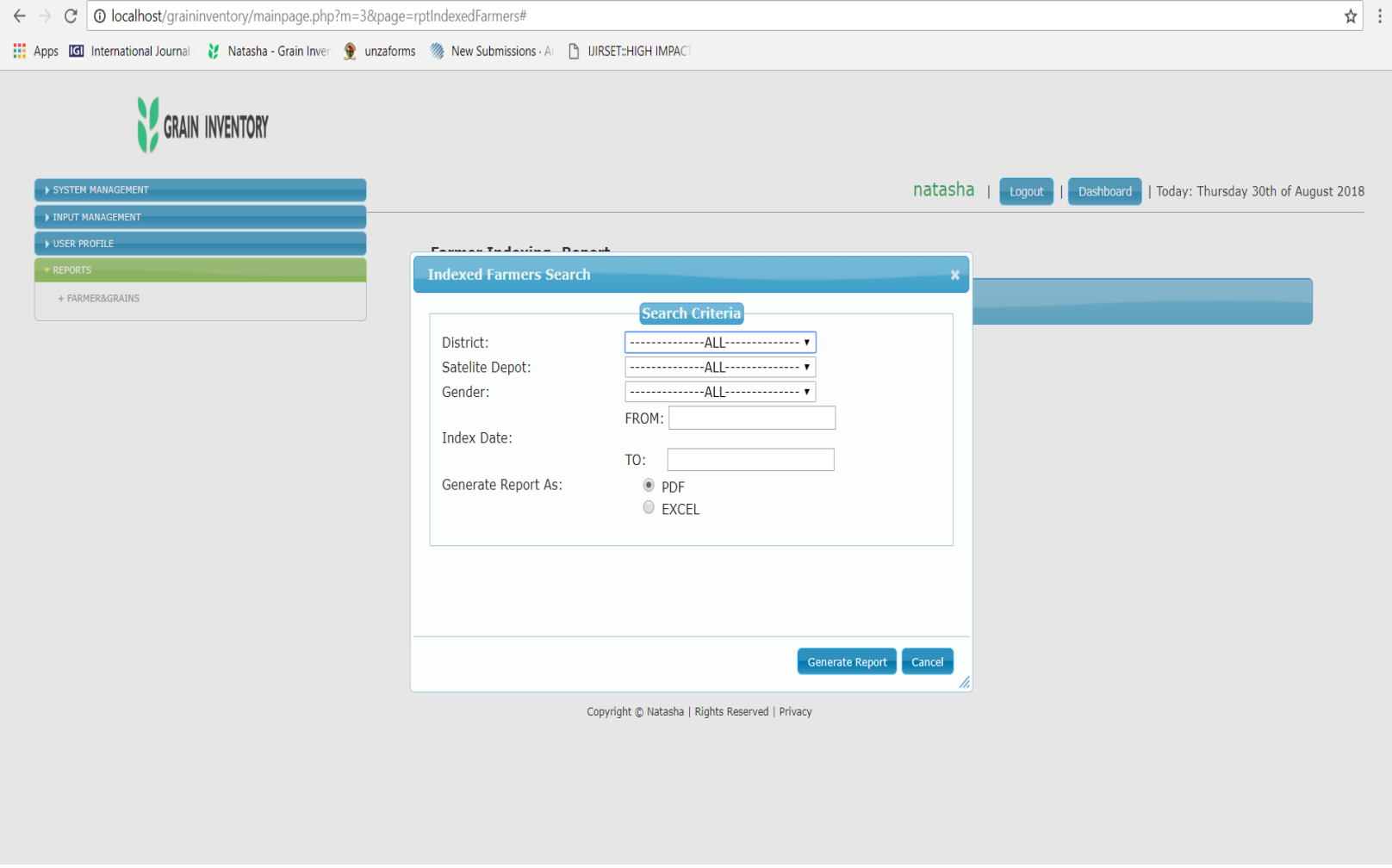

Fig. 13: querying of farmers 


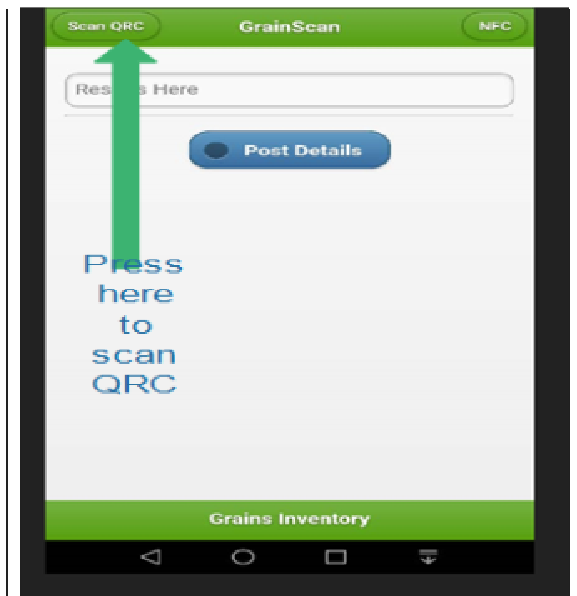

(a)

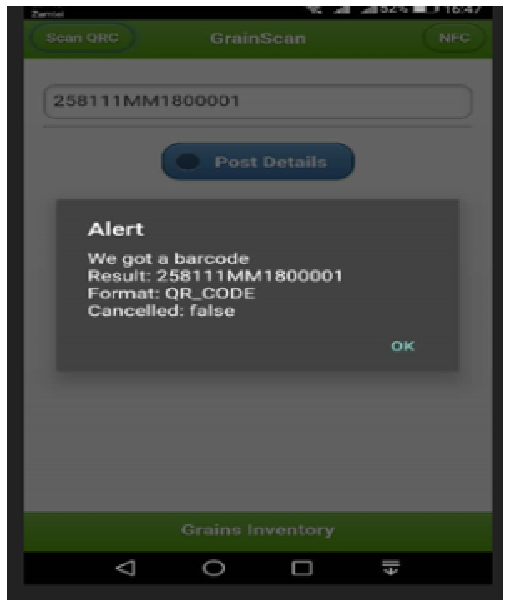

(b)

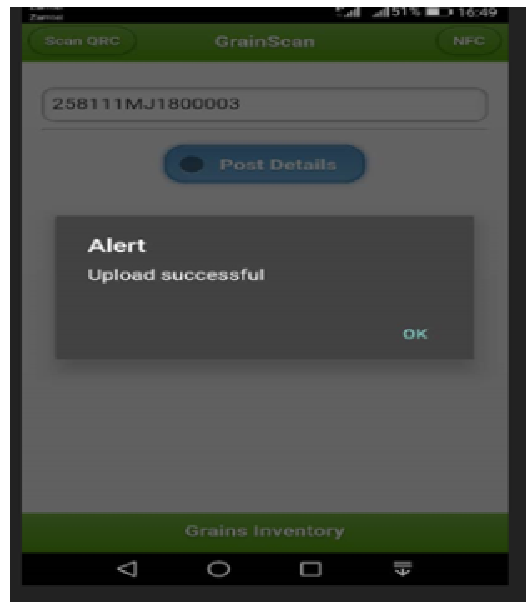

(c)

Fig. 14: Screen shots of the mobile application

If there was a problem during this process, an error prompt pop-up message will then be flashed. Figure 14c illustrates a successful upload of the $\mathrm{QR}$ code onto the server database by the mobile application. The application has customization on the server database communication, such that it can either be pointing to a local host or an online platform. Similarly, if there was a problem with posting this data, an error pop-up message is prompted.

\section{Conclusion}

- Implementing such an information management system will help manage and maintain grain inventory at the Food Reserve Agency

- The application will help not only to capture and manage inventory but also help manage satellite depots. With the ability of knowing how much stock is at a particular depot, it will provide the government benchmarks for setting up reorder levels and forecasting on the needed investment in the next seasons

- The security feature that the QR codes provide will just be another control measure to manage inventory. The codes generated will be unique and will cut out fraudulence activities, for only codes generated or present on the server will be accepted to be scanned back as net inventory

\section{Acknowledgement}

I would like to thank the following for the valuable assistance: Food Reserve Agency Zambia, The government of Zambia through the National Science and Technological Council (NSTC) for the funds and facilitating the study.

\section{Author's Contribution}

Natasha Mwansa: Design of research, acquisition of data, analysis and interpretation of data. Develop and testing of the prototype.

Jackson Phiri: Conceptual design of research, which part of the project funded by the Zambia government. Review the design and implementation for critical and significant intellectual content.

The system prototype development has replaced manual methods of inventory management with automated systems in order eliminate the challenges brought about by manual systems. In order to show how an automated inventory management system will work in FRA's inventory management, a prototype was developed to show the proof of the concept. The prototype was implemented using QRC technology to show how automated tracking of inventory can be done. As already outlined in the previous section, the prototype application named Grain Inventory consists of the web components which is the frontend and the server-side component which is the backend. The system administrator creates and manages users in the system. The user is registered in the system for them to be able to access the web-based system modules. This helps to track every activity performed by specific users in the system.

\section{Ethics}

This article is original and contains unpublished material. The corresponding author confirms that all of the other authors have read and approved the manuscript and no ethical issues involved. 


\section{References}

Borhan, N.H., C.W. Shiang, P.C. Chiu, H. Sharbini and T.P. Ping et al., 2018. An enhancement of dyslexic mobile application using sight word reading strategy: Results and findings. J. Comput. Sci., 14: 919-929. DOI: $10.3844 /$ jcssp.2018.919.929

Chang, J.H., 2014. An introduction to using QR codes in scholarly journals. Sci. Edit., 1: 113-117.

DOI: $10.6087 / \mathrm{kcse} .2014 .1 .113$

Chibuye, M. and J. Phiri, 2017. A remote sensor network using android things and cloud computing for the food reserve agency in Zambia. Int. J. Adv. Comput. Sci. Applic. DOI: 10.14569/IJACSA.2017.081150

Chin, K.Y. and Y.L. Chen, 2013. A mobile learning support system for ubiquitous learning environments. Proc. Soc. Behav. Sci., 73: 14-21. DOI: 10.1016/j.sbspro.2013.02.013

Code, Q.R., 2011. Q R code.com. http://www.densowave.com/qrcode/qrstandard-e.html

Cynthia Lubasi Muyunda, J.P., 2016. A wireless sensor network based grain inventory management system for zambia's food reserve agency. Int. J. Innovative Res. Sci. Eng. Technol., 5: 3519-3526. DOI: 10.15680/IJIRSET.2016.0503144

FRAZ, 2017. Satellite depot handbook. Food Reserve Agency Zambia, Lusaka.

Gautam, P.R., S. Ragumani and Y.K. Sharma, 2010. A system for payroll management. J. Comput. Sci., 6: 1531-1534. DOI: 10.3844/jcssp.2010.1531.1534

Han, Y.Y., K.Y. Wang, Z.Q. Liu, Q. Zhang and S.H. Panb et al., 2017. A crop trait information acquisition system with multitag-based identification technologies for breeding precision management. Comput. Electron. Agric., 135: 71-80. DOI: 10.1016/j.compag.2017.01.004
IFPI, 2014. International Food Policy and Institute. http://www.ifpri.org/topic/food-security

ISO/IEC, 2006. Information technology automatic identification and data capture techniques -Barcode symbology QR code. Switzerland.

Khunt, A.R. and P. Prabu, 2018. An empirical analysis of android permission system based on user activities. J. Comput. Sci., 14: 324-333. DOI: $10.3844 /$ jcssp.2018.324.333

MAZ, 2013. FRA 2013 crop marketing modalities. Ministry of Agriculture Zambia, Lusaka.

Narayanan, A.S., 2012. QR codes and security solutions. Int. J. Comput. Sci. Telecommun., 3: 69-72.

Nasr, A.A.E. and S.A. Elbooz, 2018. Scheduling strategies in cloud computing: Methods and implementations. Am. J. Eng. Applied Sci., 11: 426-432. DOI: 10.3844/ajeassp.2018.426.432

Simukanga, A., J. Phiri, M. Nyirenda and M. KalumbiloKabemba, 2018. E-governance systems: A case study of the development of a small-scale farmer database. Zambia ICT J., 2: 7-15.

Singh, S., 2016. QR code analysis. Int. J. Adv. Res. Comput. Sci. Software Eng., 6: 89-92.

Victor, N., 2012. Enhancing the data capacity of QR codes by compressing the data before generation. Int. J. Comput. Applic., 60: 17-21.

DOI: $10.5120 / 9663-1104$

Zhou, J., Y. Liu and A. Kumar, 2012. Research on distortion correction of QR code images. IJCST, 3: 415-420. 